\title{
ВОЗРАСТНЫЕ ОСОБЕННОСТИ ЭЛЕМЕНТНОГО СТАТУСА ДЕТЕЙ МУРМАНСКОЙ ОБЛАСТИ
}

\section{Петров В.Н., Терещенко П.С.}

${ }^{1}$ Научно-исследовательский иентр медико-биологических проблем адаптации человека в Арктике КНЦ PAH, Anamumbl, petrov_ombp@admksc.apatity.ru

\section{Аннотация}

Изучен минеральный состав волос детей проживающих в Арктической зоне России. Установлено, что элементный статус детей зависит от пола ребенка, особенностей его развития и образа жизни. Выявлены различия в химическом составе волос детей проживающих в Мурманской области по таким элементам, как: натрий, магний, алюминий, калий, кальций, марганец, медь, цинк, мышьяк, селен, рубидий, стронций, серебро, кадмий и свинец. Отмечено, что интенсивное накопление минеральных веществ в организме происходит в период полового развития ребенка.

Ключевые слова: волосы детей, минеральный состав, элементный статус, химические элементы, минерализация, токсичные и условно токсичные элементы, жесткость воды.

\section{Введение}

Дефицит жизненно важных химических элементов или их избыток, неблагоприятные климатогеографические условия могут способствовать снижению здоровья населения проживающего в Арктическом регионе [1].

По данным Н.А. Агаджанян [2], содержание химических элементов в волосах является интегральным показателем, отражающим длительное воздействие на организм человека комплекса эколого-физиологических факторов, таких как уровень содержания химических элементов, в окружающей среде, поступление их с пищей, возраст и пол, состояние пищеварения и выделительных систем организма, а также связано с местом жительства. Волосы человека накапливают химические элементы в больших количествах.

В результате проведенных сравнительных исследований было показано, что у женщин влияние элементного статуса на изучаемые показатели выражено в меньшей степени, чем у мужчин. У женщин по сравнению с мужчинами в волосах наблюдается существенно более высокое содержание $\mathrm{Ca}$ и $\mathrm{Mg}$ и низкое содержание $\mathrm{K}, \mathrm{Na}, \mathrm{Fe}[3]$.

В тканях здорового организма концентрация меди в течение всей жизни поддерживается строго постоянной. В организме существует система, препятствующая накоплению Сu в тканях путем ограничения всасывания, или стимуляции выведения.

Отмечено, что серебро (Ag) снижает сродство селена (Se) не геномным железосодержащим белкам, тем самым снижая их активность в качестве переносчиков электронов. Вызываемый серебром дефицит селена Se можно предотвратить увеличением содержания Se и токоферола (витамина Е) в диете [4].

По распространенности в природе железо (Fe) уступает только алюминию (Al). Дефицит железа во всем мире остается наиболее частой причиной анемий.

\section{Материалы и методы}

Для изучения элементного анализа проб волос были обследованы группы дошкольников и подростков с. Ловозеро и г. Апатиты Мурманской области в 2017 г.

Волосы отбирались не менее чем с пяти точек головы (затылочной, височной, теменной, лобной областей). Пряди срезались ножницами из нержавеющей стали, предварительно обработанных спиртом, в нескольких миллиметрах от корня, упаковывались в пакеты. При взятии образцов записывали возраст, пол, полное имя, адрес проживания. Волосы исследовали, согласно методике, представленной в работе [5]. Анализ данного биоматериала является наиболее удобным и отличается простотой забора и хранения биоматериала. Все образцы волос были собраны и проанализированы 
согласно требованиям МАГАТЕ и методическим рекомендациям Министерства здравоохранения СССР и Федерального центра государственного санитарно-эпидемиологического надзора РФ [6].

Полученные результаты о содержании химических элементов в волосах жителей Апатиты и Ловозеро Мурманской области сравнивали с нормативными границами содержания элементов в волосах жителей средней полосы России.

Образцы изучали по 35 элементам: Алюминий (Al), Барий (Ba), Бериллий (Be), Бор (B), Ванадий $(\mathrm{V})$, Германий $(\mathrm{Ge})$, Железо $(\mathrm{Fe})$, Йод $(\mathrm{I})$, Кадмий $(\mathrm{Cd})$, Калий $(\mathrm{K})$, Кальций $(\mathrm{Ca})$, Кобальт $(\mathrm{Co})$, Кремний (Si), Литий (Li), Магний $(\mathrm{Mg})$, Марганец (Mn), Медь (Cu), Молибден (Mo), Мышьяк (As), Натрий (Na), Никель (Ni), Олово ( $\mathrm{Sn})$, Ртуть (Hg), Рубидий (Rb), Свинец (Pb), Селен ( $\mathrm{Se})$, Серебро $(\mathrm{Ag})$, Стронций (Sr), Сурьма (Sb), Талий (Tl), Титан (Ti), Фосфор (P), Хром (Cr), Цезий (Cs), Цинк (Zn).

Исследования проводили на масс-спектрометре с индуктивно связанной аргоновой плазмой Agilent 7900, с программным обеспечением «MassHunter», с использованием печи микроволнового разложения «Mars 5». Аналитические исследования были проведены в научно-исследовательской лаборатории элементного анализа научно-исследовательского отдела биоиндикации ФГБУ «Всероссийского центра экстренной и радиационной медицины им. А.М. Никифорова» МЧС России, г. Санкт-Петербург. Для статистического анализа результатов использовали программное обеспечение Statistica 6.0.

\section{Результаты и обсуждения}

Для исследования минерального состава волос детей проживающих в различных муниципальных образованиях Мурманской области. Выбрали детей, как наиболее оседлую и не подверженную влиянию производственных факторов часть населения. В таблице 1 приведены результаты исследований по 22 химическим элементам, по которым выявлены отклонения от концентрации в волосах жителей средней полосы России. Результаты представлены в мкг/г по группам обследованных детей без учета пола ребенка.

В таблице 2 приведены данные о количестве детей с выявленными превышениями концентраций химических веществ.

Из представленных данных в таблице 2, обращает внимание то, что почти у всех обследованных детей, как у мальчиков, так и у девочек дошкольников и подростков было превышение нормы по концентрации натрия (в $100 \%$ случаев) и калия (36-80 \% случаев). Высокая концентрация магния до 50 \% отмечалась только у девочек- подростков с. Ловозера; девочек дошкольниц - 20 \%, девочек-подростков- 56 \% г. Апатиты. Такая же закономерность отмечалась у девочек дошкольниц с. Ловозера по кальцию - 57 \% и марганцу - $21 \%$, девочек дошкольниц г. Апатиты по кальцию у 27 \%, по марганцу - у 7 \%. У девочек-подростков г. Апатиты по кальцию у 56 \%, по марганцу у $11 \%$.

Особо хочется отметить частоту встречаемости высокой концентрации таких «токсичных» химических элементов как: алюминий среди девочек, как с. Ловозеро, так и г. Апатиты в пределах $22-43 \%$. В то же самое время у мальчиков различных возрастных групп и проживающих в разных населенных пунктах высокого содержания алюминия не отмечается. Свинец в повышенных концентрациях встречается у девочек дошкольниц с. Ловозера у 50 \% , а также у девочек дошкольниц г. Апатиты у $47 \%$ и девочек-подростков у $22 \%$.Повышенное содержание мышьяка встречается у мальчиков-подростков с. Ловозеро в 18 \% случаях, мальчиков дошкольников г. Апатиты - $10 \%$, девочек дошкольниц г. Апатиты - $13 \%$.

«Условно-токсичные» элементы: повышенная концентрация стронция встречается у 50 \% девочек-подростков Ловозера и 27 \% девочек дошкольниц, у 56 \% девочек-подростков г. Апатиты; превышение по олову встречается у 27 \% девочек дошкольниц г. Апатиты и в 7 \% случаев у девочек-подростков с. Ловозеро.

Превышение по кадмию и рубидию встречается у девочек и мальчиков дошкольников с. Ловозеро. Повышенное содержание кадмия выявляется у 56 \% девочек-подростков г. Апатиты. Единичные случаи встречаются у девочек и мальчиков подростков и дошкольников с. Ловозеро и г. Апатиты. 


\begin{tabular}{|c|c|c|c|c|c|c|c|c|c|}
\hline${ }^{\mathrm{qL}} \mathcal{K}_{\mathrm{I}}$ & m? & ñ & in & $\begin{array}{l}0 \\
\dot{0}\end{array}$ & సે & $\begin{array}{c}\infty \\
\vdots \\
\vdots \\
0\end{array}$ & $\frac{9}{0}$ & तึ & $\begin{array}{l}1 \\
0 \\
0\end{array}$ \\
\hline І9ІгвgоУ & $\stackrel{0}{\circ}$ & $\stackrel{\partial}{0}$ & $\stackrel{\circ}{\circ}$ & $\bar{m}$ & $\stackrel{0}{\circ}$ & $\begin{array}{l}\tilde{\theta} \\
0\end{array}$ & $\begin{array}{l}\text { d } \\
\text { Oे }\end{array}$ & $\stackrel{0}{0}$ & เి \\
\hline пой & $\stackrel{m}{0}$ & $\stackrel{m}{0}$ & $\overrightarrow{0}$ & $\overrightarrow{0}$ & $\vec{b}$ & $\stackrel{\text { cิ }}{\rightarrow}$ & $\stackrel{n}{0}$ & 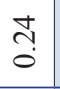 & vis \\
\hline нәгә弓 & bे & $\overrightarrow{\widetilde{o}}$ & $\begin{array}{l}n \\
0 \\
0\end{array}$ & ֶิ & $\bar{m}$ & $\begin{array}{c}0 \\
0 \\
0\end{array}$ & $\begin{array}{l}\stackrel{+}{n} \\
i\end{array}$ & రి. & \\
\hline १ॉәИ & $\stackrel{\text { ָ̦ }}{\sim}$ & $\begin{array}{l}\tilde{o} \\
\stackrel{i}{i}\end{array}$ & $\begin{array}{l}\infty \\
\infty \\
\infty \\
\end{array}$ & $\stackrel{\infty}{-}$ & $\hat{i}$ & $\begin{array}{l}\dot{N} \\
\dot{m} \\
\end{array}$ & $\begin{array}{l}\infty \\
\infty \\
\ddot{2}\end{array}$ & $\begin{array}{l}\vec{t} \\
\stackrel{0}{0} \\
-\end{array}$ & $\begin{array}{l}88 \\
i=8\end{array}$ \\
\hline неци $L$ & $\underset{\sim}{\stackrel{N}{r}}$ & $\stackrel{m}{m}$ & $\begin{array}{l}\hat{\sigma} \\
\text { in }\end{array}$ & $\underset{\infty}{\stackrel{\infty}{r}}$ & ర్రి & $\begin{array}{c}\hat{\infty} \\
\dot{n} \\
\dot{n}\end{array}$ & $\stackrel{8}{\stackrel{2}{\circ}}$ & స్తి & \\
\hline чгәяиН & $\stackrel{n}{\check{c}}$ & $\stackrel{\tilde{\theta}}{-}$ & $\stackrel{\infty}{\stackrel{\infty}{2}}$ & $\overrightarrow{\hat{0}}$ & 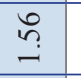 & $\begin{array}{l}n \\
0 \\
0\end{array}$ & \begin{tabular}{l}
$\infty$ \\
\hdashline \\
0
\end{tabular} & 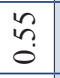 & \\
\hline dog & $\hat{n}$ & $\stackrel{i}{n}$ & $\begin{array}{c}\hat{\infty} \\
i \\
i\end{array}$ & $\begin{array}{l}3 \\
0\end{array}$ & $\stackrel{\sim}{m}$ & $\begin{array}{l}0 \\
? \\
0\end{array}$ & $\stackrel{\text { ֻे }}{\tilde{r}}$ & $\stackrel{\infty}{\stackrel{\infty}{0}}$ & 0 \\
\hline яниП & $\begin{array}{l}\text { तิ } \\
\text { రి }\end{array}$ & 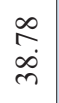 & $\begin{array}{l}\infty \\
\stackrel{0}{y} \\
\dot{y}\end{array}$ & $\begin{array}{l}\infty \\
\infty \\
\stackrel{m}{m}\end{array}$ & 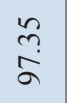 & $\begin{array}{c}\underset{\sim}{\sim} \\
\stackrel{\infty}{+}\end{array}$ & $\begin{array}{l}\infty \\
\infty \\
\end{array}$ & ¿े & $\begin{array}{l}8.8 \\
\text { ¿. } \\
\text { ¿ }\end{array}$ \\
\hline ояого & $\stackrel{\mathbb{E}}{\mathrm{S}}$ & $\stackrel{8}{-}$ & $\stackrel{\Xi}{\stackrel{J}{-}}$ & $\underset{-}{\vec{F}}$ & 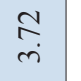 & $\stackrel{\bullet}{i}$ & $\hat{\sigma}$ & $\stackrel{t}{0}$ & \\
\hline пәнелdеW & $\bar{\sigma}$ & $\vec{J}$ & $\stackrel{\text { అి }}{-}$ & $\underset{-}{\overrightarrow{-}}$ & $\stackrel{\Xi}{\stackrel{0}{-}}$ & $\stackrel{g}{\stackrel{0}{0}}$ & $\begin{array}{l}\infty \\
\stackrel{0}{0} \\
0\end{array}$ & 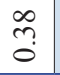 & \\
\hline ииґия Һ $_{\mathrm{d}}$ & $\stackrel{\text { Iิ }}{-}$ & $\begin{array}{l}n \\
\infty \\
0 \\
0\end{array}$ & $\begin{array}{l}\infty \\
0 \\
0\end{array}$ & $\stackrel{n}{0}$ & $\stackrel{\text { oे }}{.}$ & ڤุ & $\tilde{0}$ & $\stackrel{\infty}{\overbrace{0}^{\infty}}$ & \\
\hline яБчпाпाч| & $\stackrel{\circ}{0}$ & $\begin{array}{l}\tilde{O} \\
\tilde{0} \\
0\end{array}$ & $=$ & $\begin{array}{l}n \\
0 \\
0\end{array}$ & $\stackrel{0}{\circ}$ & $\stackrel{?}{\circ}$ & $\stackrel{0}{\stackrel{0}{0}}$ & oे & \\
\hline йитету & $\stackrel{\text { İ }}{0}$ & $\stackrel{5}{0}$ & $\stackrel{0}{0}$ & $\stackrel{\circ}{0}$ & $\overrightarrow{\widetilde{\jmath}}$ & $\stackrel{?}{\circ}$ & $\stackrel{7}{0}$ & $\stackrel{9}{0}$ & $\begin{array}{l}1 \\
\vdots \\
0 \\
0\end{array}$ \\
\hline пәнияว & $\begin{array}{l}\stackrel{?}{r} \\
\dot{m}\end{array}$ & $\underset{⿱ 亠}{i}$ & 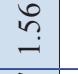 & $\stackrel{\Omega}{6}$ & రి & 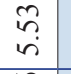 & $\stackrel{+}{\square}$ & $\stackrel{t}{G}$ & \\
\hline йинле $\mathrm{N}$ & $\begin{array}{l}\text { Jे } \\
\infty \\
\text { id }\end{array}$ & $\begin{array}{l}\text { in } \\
\text { f. } \\
\text { in }\end{array}$ & 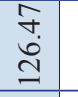 & \begin{tabular}{l}
1 \\
\multirow{2}{*}{} \\
$\Omega$
\end{tabular} & $\stackrel{\text { ले }}{\vec{n}}$ & $\begin{array}{l}0 \\
\infty \\
\stackrel{0}{0} \\
\stackrel{0}{1} \\
\end{array}$ & $\begin{array}{l}0 \\
\dot{0} \\
\infty \\
\infty\end{array}$ & $\begin{array}{l}\infty \\
\infty \\
i\end{array}$ & \\
\hline ийпноdцつ & $\begin{array}{l}0 \\
\infty \\
0\end{array}$ & $\stackrel{8}{-}$ & $\frac{n}{n}$ & $\begin{array}{l}\infty \\
\text { గె. }\end{array}$ & $\begin{array}{l}n \\
\stackrel{n}{*} \\
\dot{+}\end{array}$ & $\begin{array}{l}\stackrel{n}{a} \\
\tilde{n}\end{array}$ & $\begin{array}{l}n \\
r \\
+\end{array}$ & $\begin{array}{l}8 \\
\dot{n}\end{array}$ & on \\
\hline ийпчгеУ & $\begin{array}{l}\stackrel{g}{q} \\
\stackrel{j}{g}\end{array}$ & $\begin{array}{l}\hat{\infty} \\
\dot{m} \\
\dot{m}\end{array}$ & 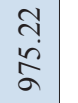 & 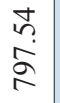 & $\begin{array}{l}\bar{m} \\
\stackrel{i}{i} \\
\stackrel{n}{n}\end{array}$ & $\begin{array}{l}\hat{A} \\
\dot{0} \\
8\end{array}$ & $\begin{array}{l}\underset{\sim}{\sim} \\
\underset{\infty}{\infty}\end{array}$ & $\begin{array}{l}\text { ஸे } \\
\text { ๙े }\end{array}$ & 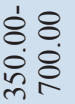 \\
\hline иинижогг & 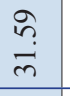 & 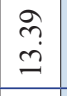 & 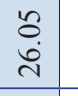 & $\begin{array}{l}n \\
\sim \\
\infty \\
-\end{array}$ & $\stackrel{\infty}{m}$ & $\begin{array}{l}\exists \\
\stackrel{\square}{2}\end{array}$ & $\stackrel{?}{\stackrel{9}{I}}$ & $\begin{array}{l}\forall \\
\stackrel{9}{2}\end{array}$ & $\begin{array}{l}18 \\
8.8 \\
\text { bे }\end{array}$ \\
\hline odgədəว & : & $\begin{array}{l}0 \\
0 \\
0\end{array}$ & $\stackrel{\vec{\sigma}}{-}$ & $\overrightarrow{\dot{r}}$ & ติ & $\begin{array}{l}\tilde{S} \\
i \\
i\end{array}$ & 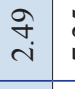 & $\stackrel{n}{\curvearrowright}$ & 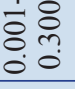 \\
\hline ийгеУ & $\begin{array}{l}\bar{m} \\
\stackrel{+}{\stackrel{\nu}{े}}\end{array}$ & $\begin{array}{l}\stackrel{\infty}{o} \\
\stackrel{J}{I} \\
\end{array}$ & $\begin{array}{l} \\
\dot{D} \\
\stackrel{ \pm}{=}\end{array}$ & $\begin{array}{l}\infty \\
\infty \\
\dot{0} \\
+ \\
\infty\end{array}$ & $\begin{array}{l}\hat{o} \\
\dot{+} \\
\tilde{\omega} \\
\text { iे }\end{array}$ & $\begin{array}{l}\tilde{N} \\
\tilde{d} \\
\mathbb{d} \\
\mathbb{I}\end{array}$ & 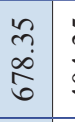 & $\begin{array}{l}\tilde{n} \\
\tilde{m} \\
\dot{t}\end{array}$ & $\begin{array}{l}18 \\
8 \\
\dot{8} \\
\dot{0} \\
0\end{array}$ \\
\hline ийцен & 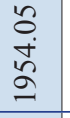 & 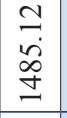 & $\begin{array}{l}\vec{J} \\
\grave{d}\end{array}$ & 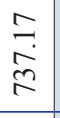 & $\begin{array}{l}0 \\
\infty \\
\infty \\
\infty\end{array}$ & $\begin{array}{l}\tilde{\sigma} \\
\dot{q} \\
\Xi\end{array}$ & $\begin{array}{l} \pm \\
\dot{8} \\
\dot{8}\end{array}$ & 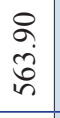 & $\begin{array}{l}1 \\
8 \\
8 \\
\end{array}$ \\
\hline 覓 & $x^{6}$ & 0 & $x^{b}$ & 0 & $x^{j}$ & 0 & $x^{6}$ & 0 & \\
\hline 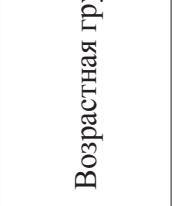 & 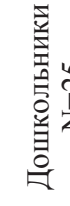 & & 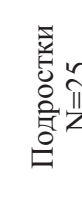 & & 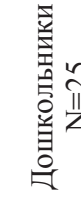 & & 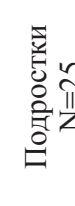 & & 嘅 \\
\hline нойа & \multicolumn{4}{|c|}{ одәєояо Г } & \multicolumn{4}{|c|}{ IqLИLСШV } & \\
\hline
\end{tabular}

\begin{tabular}{|c|c|c|c|c|c|c|c|c|}
\hline & ${ }_{\mathrm{QL}}^{\mathrm{Q}} \mathcal{K}_{\mathrm{I}}$ & 0 & 00 & 0 r & 0 & 0 & 0 & \\
\hline & І9ггеgоУ & 0 & 00 & 0 r & 0 & 0 & 0 & \\
\hline & ஈоЙ & 0 & 00 & 00 & 0 & $r$ & 0 & \\
\hline & нәгә弓 & 0 & 00 & 00 & 0 & 0 & $\simeq$ & \\
\hline & ЧाəW & 0 & 00 & 00 & 0 & $r$ & 0 & \\
\hline & нешиц & 0 & 00 & 0 r & 0 & 0 & 0 & \\
\hline & чгәяиН & a 1 & $\therefore \circ$ & a 0 & 0 & 0 & 0 & \\
\hline & dog & a 1 & $r c$ & 0 - & 0 & 0 & 0 & \\
\hline & яниП & 0 & 00 & 00 & 0 & 0 & $\simeq$ & \\
\hline & ояого & 0 & 00 & 0 - & 0 & $\hat{\imath}$ & 0 & 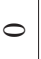 \\
\hline $0^{\circ}$ & пәнелдеЏ & 01 & $r c$ & $\circ \bar{\lambda}$ & vo & $r$ & 0 & $=$ \\
\hline 离 & ииґия $\kappa_{\mathrm{d}}$ & $\infty$ & \pm 0 & 0 - & $-ㅇ$ & 0 & 0 & c \\
\hline & яьяпाча| & 0.1 & $r \propto$ & $\infty r$ & $-ㅇ$ & 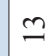 & 0 & c \\
\hline & ийтІеу & $\hat{\lambda}$ & $\vec{N} 0$ & 0 r & 으 & $r$ & 0 & in \\
\hline & пәнияว & a & inc & 0 r & 으 & 于 & 0 & $\approx$ \\
\hline & иинлеј & 0 & 00 & 0 in & 0 & ते & 0 & $n$ \\
\hline & йипноdцว & 0 & 00 & 0 in & 0 & $\hat{\imath}$ & 0 & $n$ \\
\hline & ийпчгеУ & 0.1 & -0 & 0 in & 0 & $\grave{\lambda}$ & 0 & $n$ \\
\hline & иинижогг & $0:$ & F 0 & - సे & 0 & $m$ & 0 & $\approx$ \\
\hline & odgədəว & $\stackrel{\infty}{=}$ & भ & $a$ in & กั & 8 & 0 & 5 \\
\hline & ийгеу & t) & 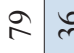 & 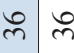 & i? & $\triangleright$ & 2 & $=$ \\
\hline & йиdıвн & 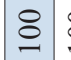 & $£ \nsubseteq$ & 8 & 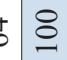 & 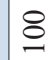 & 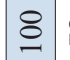 & $\infty$ \\
\hline & гоШ & $\Sigma$ & $\Rightarrow=$ & $\Sigma \approx$ & $\Leftrightarrow \Sigma$ & $\approx$ & $\Sigma$ & 不 \\
\hline & 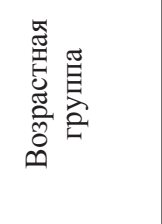 & 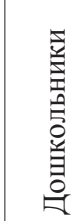 & 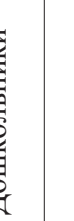 & 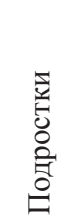 & & 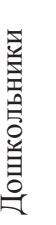 & 氕 & \\
\hline & & & də & & & & & \\
\hline
\end{tabular}


Следует отметить, что в группах девочек проживающих в г. Апатиты и с. Ловозеро, как у дошкольников, так и подростков отмечалась высокая концентрация серебра у $43 \%$ и 57 \%, соответственно, что коррелирует с количеством детей у которых превышения концентрацией селена не отмечалось. У тех мальчиков-подростков г. Апатиты, у которых отмечалась невысокая концентрация селена только в 12 \% случаев, отсутствовало превышение концентрации серебра. Можно предположить, что повышенный уровень серебра в волосах девочек отражают воздействие окружающей среды. Волосы обычно накапливают серебро при обработке их, такими веществами как красители или отбеливатели. Природу возникновение повышенного уровня серебра в волосах девочек мы пока объяснить не можем.

Отмечается превышение концентрации цинка у $11 \%$ подростков девочек и 12 \% мальчиков г. Апатиты. Цинк необходим для регенерации тканей, формирования Т- и В-клеточного иммунитета, процессов выработки антител, функций естественных клеток-киллеров [7].

Из представленных данных обращает внимание то, что сочетание таких химических веществ как: бор, алюминий, рубидий, серебро и титан и их превымение норм выявлены только у одной девочки дошкольнииы с. Ловозеро.

\section{Выводы}

Повышенная концентрация химических элементов в волосах дошкольников и подростков с. Ловозеро и г. Апатиты по таким химическим элементам как натрий и калий объясняется особенностью развития детского организма. В дошкольном возрасте продолжается рост и функциональное совершенствование всех органов и систем, развитие интеллектуальных способностей. Увеличение длины тела в год составляет в среднем 5-8 см, массы тела - около 2 кг [8]. По мере роста и развития человека минерализация его костей увеличивается, достигая оптимальных значений к концу полового созревания. Оно продолжается у мальчиков с 13 до 16 лет, у девочек - с 12 до 15 лет. В этот период наблюдается дальнейшее увеличение скорости роста, что касается всех размеров тела. В подростковом возрасте происходит перестройка основных физиологических систем организма. Темпы роста у девочек выше, чем у мальчиков. Различия в содержании повышенных концентраций таких элементов как магний, кальций, марганец, стронций, серебро и алюминий, возможно, объясняется интенсивностью роста девочек этого возраста.

Почти для всех северных территорий характерны слабоминерализованные мягкие питьевые воды и почвы с бедным микроэлементным составом [9]. Ранее в нашей статье было показано, что взаимосвязи между химическим составом, жесткостью (низкой концентрацией кальция и магния) питьевой воды, подаваемой населению Мурманской области, и уровнем заболеваемости населения данного региона не выявлено [10]. Однако следует отметить, что при низкой концентрации минеральных солей в питьевой воде Кольского полуострова, высокая концентрация этих элементов встречается в организме детей. Значительное присутствие алюминия в водах Мурманской области, употребляемых населением, отражается и на концентрации этого элемента в организме девочек дошкольниц и подростков с. Ловозеро и г. Апатиты [11]. Особо следует отметить, что поступления свинца в организм возможно с ягодами, собираемые вблизи дорог, особенно около горнорудных карьеров, где работают тяжелая техника. Мышьяк, возможно, попадает в организм при употреблении продуктов сельского хозяйства, обработанных химикатами на основе мышьяка. При этом необходимо принимать во внимание, что значительная часть продуктов поступает в районы Крайнего севера из различных регион России, а также из зарубежных стран. Природу возникновение повышенного уровня серебра в волосах девочек мы пока объяснить не можем. Необходимо отметить, что интерпретация полученных данных по элементному составу волос зачастую затруднительна по причине многофакторности воздействий и особенностей реакции организма.

\section{Литература}

1. Агаджанян Н.А. «Экологический портрет человека на Севере / Н.А. Агаджанян, Н.В. Ермакова // М.: Крук. 1997. 206 с. 
2. Агаджанян Н.А. Элементный портрет человека: заболеваемость, демография и проблема управления здоровьем нации / Н.А. Агаджанян, А.В. Скальный, В.Ю. Детков // Экология человека. 2013. № 11. C. 3-12.

3. Бонитенко Е.Ю. Элементный статус населения России Ч.1. Общие вопросы и современные методические подходы к оценке элементного статуса индивидуума и популяции / Бонитенко Е.Ю. (и др.); под ред. А.В. Скального, М.Ф. Киселева // Спб.: Медкнига «ЭЛБИ-СПб». 2010. 416 с.

4. Барашков Г.К. Медицинская бионеорганика. Основы, аналитика, клиника / Г.К. Барашков // М.: Изд-во «БИНОМ». 2011. С. 512.

5. Скальный А.В. Оценка элементного статуса популяции в генетической донозологической диагностике / А.В. Скальный, В.А. Демидов, М.Г. Скальная // Вестник СПб ГМА им. И.И. Мечникова. 2001. № 2-3 (2). С. 64-67.

6. Методические указания. М.: Федеральный центр Госсанэпиднадзора Минздрава России, 2003. С. 56.

7. Скальная А.В. О пределах физиологического (нормального) содержания $\mathrm{Ca}, \mathrm{Mg}, \mathrm{P}, \mathrm{Zn}$ и $\mathrm{Cu}$ в волосах человека / М.Г. Скальная, В.А. Демидов, А.В. Скальный // Микроэлементы в медицине. 2003. C. $5-10$.

8. Безруких М.М. Возрастная физиология (физиология развития ребенка) / М.М. Безруких, В.Д. Сонькин, Д.А. Фарберг // 4-е издание. Изд-во: «АСADEMA». 2010. С. 115.

9. Федорец Н.Г. Почвы Карелии: геохимический атлас / Н.Г. Федорец [и др.] отв. ред. В.И. Крутов Рос. акад. наук, Карел. науч. центр. Ин-т леса // М.: Наука. 2008. 44 с.

10. Петров В.Н., Терещенко П.С., Мегорский В.В. Сравнительный анализ уровня заболеваемости населения и минерального состава воды артезианских скважин в Арктической зоне и средней полосе России // Вестник КНЦ РАН. Апатиты. 2017. № 4 (9). С. 28-35.

11. Петров В.Н., Терещенко П.С., Мегорский В.В. Изучение влияния минерального состояния питьевой воды на уровень заболеваемости населения в Апатитско-Кировском регионе Мурманской области // Морская медицина. Санкт-Петербург. 2017. Т. 3. № 3. С. 86-93. 